\title{
CREATION OF A BIOMECHANICAL MODEL OF THE FOOT AND ANKLE JOINT COMPLEX
}

\author{
Freitas F. A. S. ${ }^{1}$, Salviano. R. F. ${ }^{2}$, Rocha. D. N. ${ }^{2}$, Pinotti. D. Author ${ }^{2}$
}

${ }^{1}$ Department of Physical Therapy, School of Physical Education, Physical Therapy and Occupational Therapy at the Federal University of Minas Gerais (flaviasilveiraf@ gmail.com)

${ }^{2}$ Department of Mechanical Engineering, Engineering School at the Federal University of Minas Gerais

\begin{abstract}
Introduction:The use of tridimensional biomechanical models allows the simulation of articular movements and also stress and strenght analisis on the tissues. The foot and ankle are a stable base of support for the body, provides shock absorption and propulsion of the body during gait, therefore, the creation of a model for this complex joint is indeed needed. . Objective: This study aims to develop a 3D biomechanical model of the joint complex of the foot and ankle. Orientation and relation between bones and ligaments will be demostrated and may be used in future biomechanical simulations through the model. Methods: This model is formed by skin and bones from the joint complex foot and ankle, besides the ligaments of the subtalar and talocrural joints. In order to be built, images of cadavers were used from the Visible Human Project ${ }^{\circledR}$. First, the bone structures were marked by dots and then imported by the software Solidworks ${ }^{\circledR}$. The bone accident referring to the origin and insertion of each ligament was marked on the $3 D$ geometry and those dots were connected with strips, with its characteristical disposition and thickness, forming one by one the ligaments. Results: Buiding the model makes it possible that an optimized view of bones and ligaments be simultaneously made, presenting an advantage ahead of the models built from CT scans and MRI. The great anatomic representativity of the model may be useful in cirurgic simulations, injury treatment, anatomy teaching and radiology, in the ergonomic and sportive areas, besides the production and perfecting of orthesis, protesis and shoes. Furthermore, bone accidents are recognizable (the articular space and the morphology and disposition of the $3 D$ ligaments) and it showcases an advance in the sense of having more precise ligaments, which connect bones and aid the stability of the joint and the anatomic movement control. Conclusion: The model built in this study can be usefull in many aspects of the healthy field, for example, in the creation of orthesis and protesis. Besides, the use of biomechanics simulation makes the ligamentar tension distribution analisys possible, which can be usefull in the injury prevention and treatment.
\end{abstract}

Keywords: Solidworks ${ }^{\circledR}$, foot and ankle, 3D biomechanical model 


\section{INTRODUCTION}

The use of biomechanical models have been more and more frequent in the study of constitution of the human body. Through these models, joint movements can be reproduced and strength and stress analysis made. As the ankle and feet are the stable base of support of the body, they provide chock absorption and propulsion during the march. A creation of a 3D model of that articular complex is, therefore, required

The biomechanical models can be simple or complex. Their application, however, always aims to obtain a simple representation that can be manipulated and interactively visualized on a computer, in order to reproduce the human body movements. With technology development, the models have become fundamental tools to the analysis of human body behavior, having applications in medicine, in procedures such as surgical simulations, lesion treatments, anatomy teaching and radiotherapic treatments [1]. In possession of the $3 \mathrm{D}$ geometry, a doctor can fully comprehend the nature of the lesion and define its extension and position in any angle and direction, rotating the model. The geometry can help a surgeon select the most suitable technic to be used in the operation. Its applications extend to other fields, as the ergonomic [2] and the sportive ones. Furthermore, these models allow the production and perfectioning of orthotics [3], prosthesis [4; 5] and footwear [6].

The literature describes dynamic and static biomechanical models that aid in the comprehension of strengths involved in the behavior of the human body. [7; 8; 9]. Countless researches are being conducted for the development of advanced image capturing technics for creating biomechanical models. One methodology uses image exams, such as CT scans and MRIs to acquire images [10]. However, the soft tissues cannot be displayed with X-Rays and bones are not that easily recognizable with MRI. Hence the use of real images from the Visible Human Project ${ }^{\circledR}$ in this study. In this way, soft tissues and bones can be displayed simultaneously in all of their angles.

This study was conducted at the Laboratory of Bioengineering of the Federal University of Minas Gerais, aiming to develop a biomechanical tridimensional model of the foot and ankle joint complex. Through the model, the orientation and relation between the bones and ligaments will be demonstrated and it may be used in future biomechanical simulations.

\section{METHODOLOGY}

The 3D biomechanical model of the foot and ankle built at the Laboratory of Bioengineering of the Federal University of Minas Gerais is formed by skin and bones of the foot and ankle articular complex and ligaments of the subtalar and talocrural joints. For its elaboration, the Human Visible Project ${ }^{\circledR}$ was used. It is a collection of transverse images from corpses. A license deal between the Mechanical Engineering Department of the Federal University of Minas Gerais and the National Library Medicine made these images available for use in the study. 
Once the images of the foot and ankle had been identified, their bone structures were marked by dots, as seen in the figure 1 below.

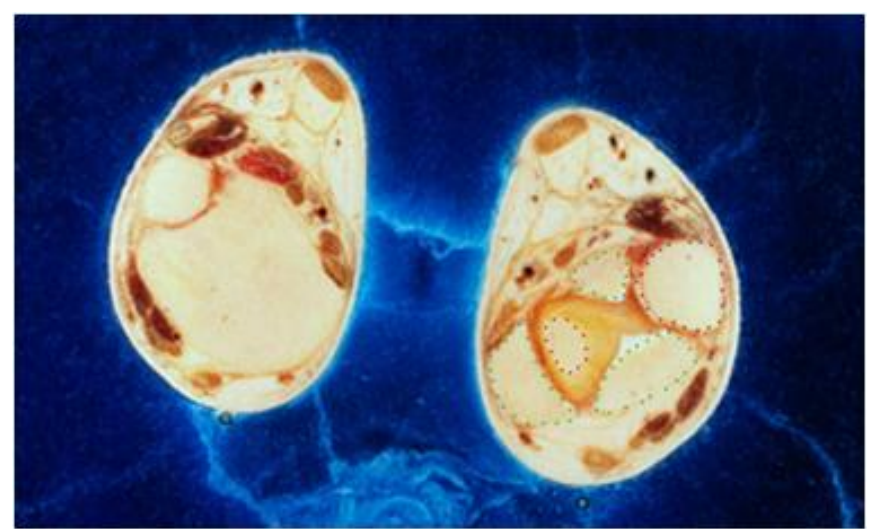

Figure 1: Geometry identification. Notice that the green marking represents the tibia , the fibula is marked in purple and the talus in orange.

The biodimensional images provided by the Visible Human Project ${ }^{\circledR}$ were imported by the software SolidWorks ${ }^{\circledR}$ for the creation of the 3D geometry. The program creates equidistant planes according with the number of imported images and estimates the real distance between each transverse image. While imported, each image assumes an orientation corresponding to its real plane, as represented in figure 2.

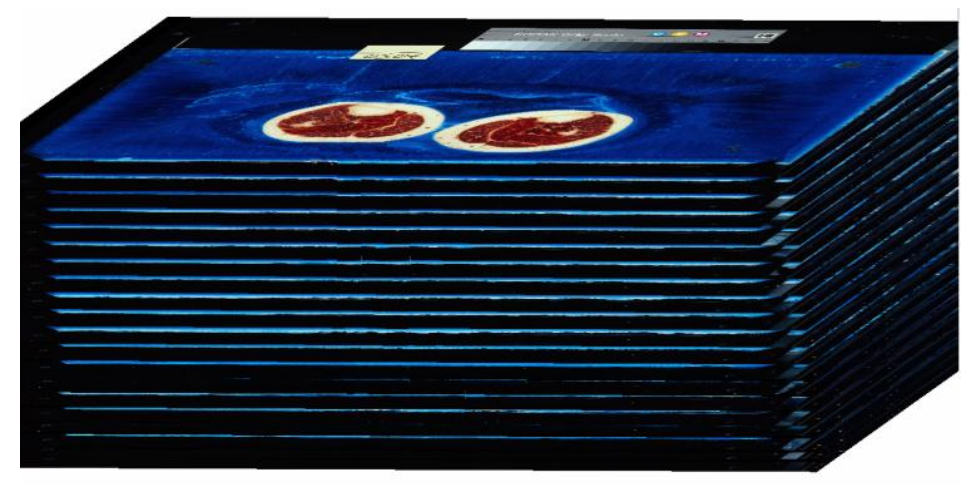

Figure 2: Overlaid images in their equidistant planes.

The dots previously marked are then connected by a spline to outline the structures in each image. The profiles of each represented bone are united through guidelines that orientate the formation of the solid, shaping the 3D geometry. The image 3 shows the geometry in three dimensions of the tibia. 


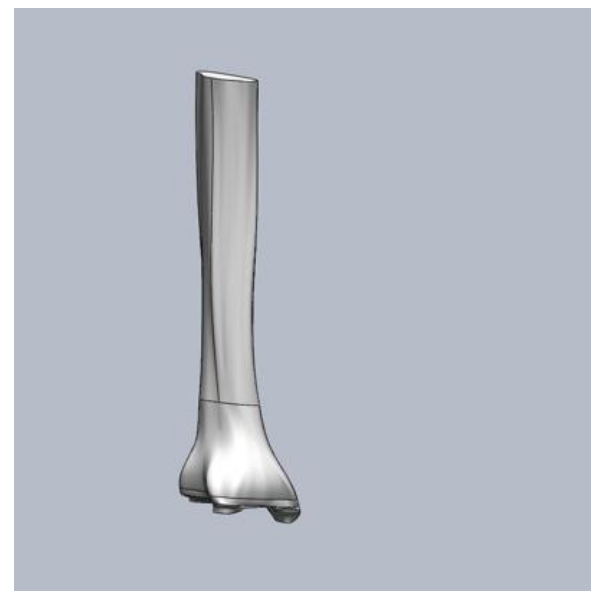

Figure 3: 3D model of the tibia

The images of a few of the bone structures, such as the phalanges, were built from sections perpendicular to the originals provided by the Human Visible Project. These images were built in the sagittal plane, following the process described by Rocha, 2011 [3]:

"An algorithm was implemented using the software Matlab $®$ to create the new sections from images of the Visible Human Project $®$. Each transverse section represents a bidimensional matrix of pixels formed by lines and columns. The algorithm piles the transverse sections in paralel planes, in a way that a new dimension named "level" was added, making a tridimensional matrix of pixels. Thereby, the union of the same column from all levels represents a frontal section, while the union of the same line of all levels representes the sagittal section. Therefore, a new biodimensional matrix is created from the selected column or line and later converted in image."

(Rocha, 2011, p52)

This process was required because the structures are complex, small and difficult to visualize through transversal images. In the Figure 4, there is a comparison between the profiles built using images created in the sagittal plane (falange I) and the original transversal images (Falanges II to V).

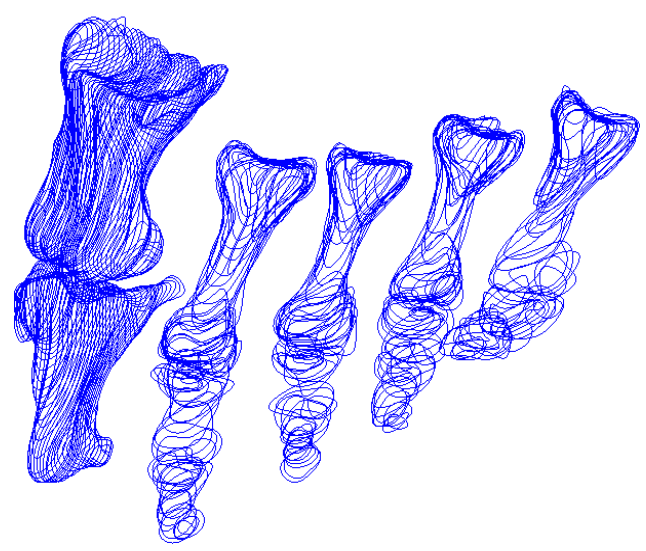

Figure 4: Comparison between the images in the sagittal and transversal planes. 
Once the bones were finished, the ligaments started to be built using the software SolidWorks ${ }^{\circledR}$. The specific characteristics of each ligament from the talocrural and subtalar joints, such as origin and insertion [11], anatomic description [12] and thickness [13;14] were researched in the literature to confirm their position in the images.

The bone accident refering to the origin and insertion of each ligament was marked in the 3D geometry, and these dots were connected by strips, with their individual disposition and thickness, forming the corresponding ligament.

\section{RESULTS AND DISCUSSION}

The construction of the biomechanical model of the foot and ankle using the images from the Visible Human Project ${ }^{\circledR}$ provides a optimized visualization of the bones and soft tissues simultaneously, presenting an advantage in comparison to the models constructed from CT scans and MRIs.

The good anatomical representativeness of the model can be useful in simulations and applications in the fields of medicine, academics and ergonomics. Among othres, bone acidents, the joint space and the disposition of ligaments can be distinguished in the model. In numerous studies $[6 ; 15]$ the model ligaments are lines that do not respect their true morphology. In that sense, the model of this study represents an advance, for its ligaments connect bones and aid the stabilization of the joint and also the control of the anatomical movements. The finished model can be seen in the figure 5, after the ligaments were added.

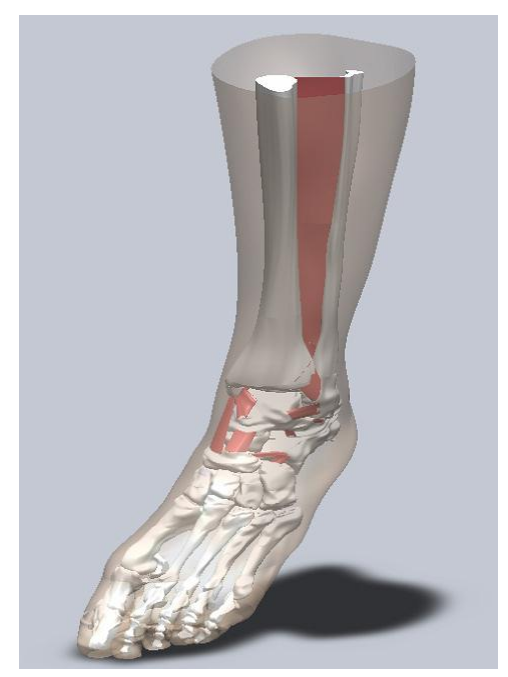

Figure 5: the finished model

Simulation studies using the finit elements method can predict the tissue deformation, the interfacial pressures, the movement of bones and joints and the internal load distribution. [16]. Therefore, complementary research using simulation is needed for a greater application of the biomechanical properties of the model. 


\section{CONCLUSION}

In the present study, a 3D biomechanical model of the joint complex foot and ankle was created through the images provided by the Human Visible Project and with the software SolidWorks@. This model can be useful in future studies in orthotics and prosthesis, in addition to having several applications in the health department. Moreover, studies of biomechanical simulations using this model can quantitatively analyse ligamentar stress distribution, being useful in the prevention and correction of lesions.

\section{Acknowledgements}

Authors would like to thank Capes, CNPq and Fapemig for the financial support.

\section{REFERENCES}

[1] Júnior, A.W., Hounsell, M.S., "Representação de humanos virtuais”. Universidade do Estado de Santa Catarina.

[2] Cox, S. L.; Mithraratne, K.; Smith, N. P., "An anatomically based finite element model of the lower limbs in the seated posture". Conf.Proc.IEEE Eng Med.Biol.Soc., vol. 2007, pag. 6327-6330, 2007.

[3] Rocha, D.N., "Desenvolvimento de modelos biomecânicos tridimensionais do membro superior: mão e cotovelo". Tese de Doutorado. Departamento de Engenharia Mecânica, Universidade Federal de Minas Gerais, 2011.

[4] Mak, A.F.T.; Zhang, M; Boone, D.A., "State-of-the-art research in lower-limb prosthetic biomechanics-socket interface". Journal of Rehabilitation Research and Development Vol. 38 No. 2, March/April 2001, 2001.

[5] Silver-Thorn, B.M., Childress, D.E., "Parametric analisyng using the finite element method to investigate prosthetic interface stress for persons with trans-tibial amputation". Journal of Rehabilitation Research and Development Vol . 33 No . 3, July 1996 Pages 227-23, 1996.

[6] Cheung, J.T.; Zhang, M., "Finite element modeling of the human foot and footwear." ABAQUS Users 'conference., 2006.

[7] Da Cunha, F. L.; Schneebeli, H. J.; Dynnikov, V. I., "Development of anthropomorphic upper limb prostheses with human-like interphalangian and interdigithal couplings". Artificial Organs, VOL 24,193-197., 2000

[8] Dandeakr, K.; Raju, B. I.; Srinivasan, M. A. "3-D finite element models of human and 
monkey fingertips to investigate the machanics of tactile sense." Journal of Biomechanical Engineering, Vol 125, 682-691., 2003.

[9] Lee, S.W.; Zhang, X. "Biodinamic modeling, system identification, and variability of multi-finger movements". Journal of Biomechanics, Vol 40, 3215-3222. (2007)First A. A., Second B. B., "Example of nice winter weather". Int. J. Winter Weat. 7, 8-13, 2012.

[10] Santos, L.R.; et al., "Criação de um modelo biomecânico da articulação do cotovelo utilizando o método dos elementos finitos". The $6^{\text {th }}$ Latin American Congress of Artificial Organs and Biomaterials, 2010.

[11] Netter, F. H.; Collacino, S., "Atlas of human anatomy”. Medical Education Division; CIBA Pharmaceutical Company. (1989)

[12] Golano,P., et al., "Anatomy of the ankle ligaments: a pictorial essay". Knee Surg Sports Traumatol Arthrosc (2010) 18:557-569 DOI 10.1007/s00167-010-1100-x., 2010.

[13] Dimmick,S.; Kennedy, D.; Daunt, N., "Evaluation of thickness and appearance of anterior talofibular and calcaneofibular liagaments in normal versus abnormal ankles with MRI”. Journal of Medical Imaging and Radiation Oncology (2009) 52, 559-563, 2009.

[14] Mkandawire, C.; Ledoux, W.R.; Sangeorzan, J.B.;MD;Ching, R.P., "Foot and ankle ligament morphometry". Journal of Rehabilitation Research \& Development Vol 42, Number 6, Pages 809-820, November/December, 2005.

[15] Yu, J., et al., "Development of a finite element model of female foot for high-heeled shoe design”. Clinical Biomechanics 23 (2008) S31-S38, 2008.

[16] Cheung, T.J.; Nigg, B.M., "Clinical applications of computacional simulation of foot and ankle”. Sportorthopa“ die Sporttraumatologie 23, 264-271 (2007)

[17] Other A. A., Other B. B., "Example of good quality illustrations". Int. J. Quality Illustr. $7,8-13,2012$. 